\title{
VARIABILIDADE GENÉTICA DE ETNOVARIEDADES DE MANDIOCA EM REGIÕES GEOGRÁFICAS DO BRASIL
}

\author{
Maria Inez Fernandes Faraldo ${ }^{1,4} ;$ Rainério Meireles da Silva ${ }^{1,4}$; Akihiko Ando ${ }^{2 *}$; Paulo Sodero Martins ${ }^{3}$ \\ ${ }_{2}^{1}$ Pós-Graduanda do Depto. de Genética - USP/ESALQ. \\ ${ }^{2}$ Depto. de Genética - USP/ESALQ, C.P. 83 - CEP: 13400-970 - Piracicaba, SP. \\ ${ }^{3}$ Depto. de Genética - USP/ESALQ - In memoriam \\ ${ }^{4}$ Bolsista CAPES. \\ *Autor correspondente <ando@cena.usp.br>
}

RESUMO: O manejo empregado nas roças de agricultura autóctone, utilizando etnovariedades de mandioca (Manihot esculenta Crantz), apresenta papel de destaque na conservação in situ dos recursos genéticos. 0 presente trabalho teve por objetivo analisar a distribuição da variabilidade genética de 141 etnovariedades de mandioca coletadas em roças de diferentes regiões geográficas do Brasil, através de marcadores isoenzimáticos, revelados a partir de eletroforese em gel de amido. Foram avaliados 11 sistemas isoenzimáticos. Dos 15 locos polimórficos analisados a heterozigosidade média observada foi de 0,354. A estimativa coeficiente de diferenciação genética $\mathrm{G}_{\mathrm{ST}}$ apresentou valor médio de $8,80 \%$ da variabilidade genética entre as regiões. $\mathrm{Na}$ análise de agrupamento, observou-se a formação de 3 grupos distintos; o primeiro formado pelas roças originadas da Região Amazônica; o segundo constituído pelas roças do Estado de São Paulo; e o terceiro composto pelas roças originadas da Reserva Indígena do Xingu. A maior parte da variabilidade genética das etnovariedades de mandioca revelou-se concentrada dentro das regiões geográficas, confirmando as pressuposições existentes no modelo de dinâmica evolutiva para a espécie.

Palavras-chave: Manihot esculenta, isoenzima, dinâmica evolutiva, roça

\section{GENETIC VARIABILITY OF LANDRACES OF CASSAVA IN GEOGRAPHICAL REGIONS OF BRAZIL}

\begin{abstract}
The management practices used in authoctonous agriculture with landraces of cassava (Manihot esculenta Crantz) play an important role in the in situ conservation of genetic resources. The objective of this work was to analyze the genetic variability present in 141 landraces of cassava, collected in gardens of different geographical regions of Brazil using isozyme techniques visualized by starch gel electrophoresis. Eleven enzymatic systems were analised. Of the 15 polymorphic loci evaluated the observed mean heterozigosity was 0.354 . $\mathrm{G}_{\mathrm{ST}}$ estimates presented a value of $8.80 \%$ for the genetic variability between regions. In cluster analysis, three distinct groups were observed: the first group was formed by the gardens of the Amazon; the second group consisted of gardens of São Paulo State; and the third group was formed by the gardens of the Xingu region. Most of the genetic variability of cassava landraces was restricted within the geographical regions, which confirmed the evolutionary dynamic model for this species.
\end{abstract}

Key words: Manihot esculenta, isoenzyme, evolutionary dynamic, garden

\section{INTRODUÇÃO}

O gênero Manihot é um taxon americano com o centro de origem e domesticação ainda em discussão. Duas espécies apresentam importância econômica: a Manihot esculenta Crantz (mandioca), com raízes tuberosas para produção de farinha, amido e consumo in natura, e M. glaziovii, para produção de látex. A mandioca é frequentemente cultivada em roças de agricultura autóctone por apresentar bom desenvolvimento em solos pobres, resistência a pragas e doenças e adaptação em diferentes regiões edafoclimáticas (Hershey, 1992).

A mandioca é cultivada em terras baixas $(<2000$ $\mathrm{m}$ ) das regiões equatoriais ou tropicais, principalmente no Brasil (com destaque para as regiões Norte, Nordeste e Centro-Oeste). No Oeste da Índia, África e nos países asiáticos, o cultivo é mais recente (Hershey e Amaya, 1989).
A grande variabilidade genética existente nas roças de etnovariedades apresenta características favoráveis para a conservação in situ e estudos de diversidade genética e evolução. As roças são adequadas para o manejo de agricultura sustentável. As plantas cultivadas, principalmente etnovariedades, representam uma forma de recurso genético que deve ser preservado e conservado, pois poderá ser utilizado pelos melhoristas em programas de melhoramento, especialmente na transferência de caracteres qualitativos.

A agricultura autóctone ou agricultura tradicional é um termo utilizado na literatura para designar o sistema agrícola cujas bases técnicas reportam ao Brasil pré-colonial, mantida pelas populações indígenas remanescentes e populações que assimilaram a técnica transmitida culturalmente por seus antepassados. Essas técnicas vão sendo adaptadas aos ecossistemas das regiões onde são praticadas. 
Segundo Plucknett et al. citados por Cleveland et al. (1994), a importância da mandioca, sob o ponto de vista genético, nesse sistema de agricultura está relacionada à presença de grande número de etnovariedades por roça, sendo importante fonte de diversidade genética, principalmente para características específicas (únicas) não encontradas nos materiais melhorados.

Os termos landraces, folk variety ou primitive variety têm sido definidos como populações ecológica ou geograficamente distintas originadas a partir de seleção local realizada pelos agricultores (Cleveland et al., 1994). No entanto, para maior uniformização terminológica será utilizado o termo etnovariedade, sugerido por Martins ${ }^{1}$.

Estratégias para conservação e preservação de recursos genéticos in situ necessitam ser planejadas, principalmente para evitar erosão genética. Deverá ser dado ênfase à conservação da diversidade genética presente nas formas de agricultura tradicional. São necessários estudos para melhor compreensão do manejo agrícola das roças, da diversidade, dos processos envolvidos com a dinâmica evolutiva das etnovariedades e suas interações com os aspectos culturais, econômicos e ecológicos das comunidades tradicionais. O modelo de dinâmica evolutiva da mandioca, proposto por Cury (1993) e Martins ${ }^{1}$, pressupõe que a roça é a unidade básica evolutiva, local onde atuam os processos de geração, amplificação e manutenção da variabilidade genética, portanto indicando que a variabilidade genética está concentrada dentro da roça.

Dentro desse contexto, o objetivo do presente trabalho foi analisar a estrutura da variabilidade genética de etnovariedades de mandioca coletadas em roças de diferentes regiões geográficas do Brasil.

\section{MATERIAL E MÉTODOS}

O presente trabalho foi conduzido a partir de 141 amostras de etnovariedades de mandioca e a variedade melhorada Mantiqueira, proveniente do Instituto Agronômico de Campinas-SP - IAC. As etnovariedades foram coletadas em roças de agricultura autóctone, localizadas em sete diferentes regiões geográficas do Brasil, como: Rio Negro (25) e Rio Solimões (15), no Estado do Amazonas-AM; Rio Branco (9), no Estado de Roraima-RR; área do Parque Indígena do Xingu (17) e comunidades de Cuiabá (22), no Estado do Mato GrossoMT; municípios de Monte Alegre, Óbidos, Santarém e Belém localizados no Estado do Pará (40); e litoral sul do Vale do Ribeira, no Estado de São Paulo (14).

Nas roças foram coletadas etnovariedades identificadas pelo agricultor, como diferentes, portanto, caracterizando uma amostragem com modelo fixo e direcionado, conforme critério de Hershey (1992) e Martins (1994).
O material (folhas recém expandidas) foi coletado no campo (Estação Experimental de Anhembi, localizada no município de Anhembi-SP, pertencente à USP/ESALQ), a partir de plantas com aproximadamente 12 meses de idade, que fazem parte da coleção de germoplasma de mandioca. As folhas coletadas foram transportadas para o laboratório de Ecologia Evolutiva e Genética Aplicada da USP/ESALQ, localizado em Piracicaba-SP, em caixinhas de plástico mantidas em gelo dentro de caixa térmica.

As enzimas foram extraídas a partir de, aproximadamente, $0,2 \mathrm{~g}$ de tecido vegetal macerado em 5 gotas de solução tampão de extração (Scandalios, 1969) e os marcadores bioquímicos (isoenzimas), revelados a partir de eletroforese em gel de amido de milho (Alfenas et al., 1991 e Ferraz et al., 1994).

Foram utilizadas três sistemas de tampão gel/ eletrodo: sistema CM, descrito por Clayton \& Tretiak (1972), sistema TC (Soltis et al., 1983) e sistema AB (Wendel \& Weeden, 1990).

As corridas eletroforéticas foram realizadas em temperatura de aproximadamente $4^{\circ} \mathrm{C}$, utilizando corrente constante de $20 \mathrm{~mA}$ por 30 minutos e $40 \mathrm{~mA}$ até o final da corrida. A voltagem inicial (pré corrida) para o sistema $A B$ foi de 150 Volts; para o sistema TC foi de 70 Volts e para o sistema CM de 100 Volts. Após meia hora, as voltagens foram alteradas para 280 Volts, 110 Volts e 150 Volts, respectivamente. Os papéis de filtro com as amostras eram retirados 30 minutos após o início da migração. $O$ tempo de corrida era de aproximadamente 8 horas, quando o marcador de bromofenol atingia $8 \mathrm{~cm}$ de migração.

Após o término da corrida, os géis foram cortados com fio de nylon de 0,20 mm em 5 fatias de $1,5 \mathrm{~mm}$ de espessura, e realizada a coloração histoquímica. Foram analisados 11 sistemas enzimáticos (TABELA 1).

As estimativas dos índices de diversidade genética, como número médio de alelos por loco $(A)$, heterozigosidade média observada $(\mathrm{Ho})$ e esperada $(\mathrm{He})$ e índice de fixação $(\mathrm{F})$, foram obtidas para as 7 regiões geográficas estudadas. As estimativas foram calculadas a partir das freqüências alélicas, estimando-se, também, o coeficiente de diferenciação genética $\left(\mathrm{G}_{\mathrm{ST}}\right)$ (Nei, 1973), utilizando o programa BIOSYS-1 (Swofford \& Selander, 1989).

\section{RESULTADOS E DISCUSSÃO}

O número de trabalhos publicados que apresentam padrões eletroforéticos de isoenzimas em espécies do gênero Manihot é pequeno, sendo algumas vezes contrastantes em relação ao padrão de bandas obtidos e número de locos (Ramirez et al., 1987; Hussain et al., 1987; Lefèvre \& Charrier 1993a, 1993b; Faraldo, 1994; Borsoi Filho, 1995; Peroni, 1998; Sambatti, 1998).

'MARTINS, P.S. (ESALQ/USP. Departamento de Genética, Piracicaba). Comunicação pessoal, 1994. 
TABELA 1 - Sistemas enzimáticos utilizados para estudos da variabilidade genética de mandioca provenientes de diferentes regiões brasileiras.

\begin{tabular}{|c|c|c|}
\hline Enzima & Código* & Sigla \\
\hline $\begin{array}{l}\text { Citosol } \\
\text { aminopeptidase }\end{array}$ & E.C. 3.4 .11 .1 & CAP \\
\hline Fosfatase ácida & E.C. 3.1.3.2 & $A C P$ \\
\hline Fosfogluco mutase & E.C. 2.7.5.1 & PGM \\
\hline $\begin{array}{l}\text { Fosfoglucose } \\
\text { isomerase }\end{array}$ & E.C. 5.3.1.9 & PGI \\
\hline Enzima málica & E.C. 1.1 .1 .40 & $\mathrm{ME}$ \\
\hline $\begin{array}{l}\text { Glucose-6-fosfato } \\
\text { desidrogenase }\end{array}$ & E.C. 1.1.1.49 & G6PDH \\
\hline $\begin{array}{l}\text { Aspartato } \\
\text { aminotransferase }\end{array}$ & E.C. 2.6.1.1 & AAT \\
\hline $\begin{array}{l}\text { Isocitrato } \\
\text { desidrogenase }\end{array}$ & E.C. 1.1.1.42 & IDH \\
\hline $\begin{array}{l}\text { Malato } \\
\text { desidrogenase }\end{array}$ & E.C. 1.1.1.37 & $\mathrm{MDH}$ \\
\hline $\begin{array}{l}\text { Manitol } \\
\text { desidrogenase }\end{array}$ & E.C. 1.1.1.67 & MADH \\
\hline $\begin{array}{l}\text { Xiquimato } \\
\text { desidrogenase }\end{array}$ & E.C. 1.1.1.25 & SKDH \\
\hline
\end{tabular}

O tecido de folhas recém-expandidas apresentou bom padrão eletroforético para 11 sistemas enzimáticos (AAT, CAP, MDH, MADH, SKDH, PGI, ME, ACP, G6PDH, IDH e PGM), apresentando os melhores zimogramas (TABELA 1). O sistema enzimático glutamato desidrogenase (GTDH), embora apresentasse bom padrão eletroforético, foi descartado das análises por que não apresentou a forma heterozigota, conforme, também, constatado por Silva (2000) que analisou a planta matriz e progênies.

Nos sistemas analisados constatou-se a existência de 15 locos polimórficos, 37 alelos e a identificação de 60 padrões fenotípicos nas 141 etnovariedades e variedade Mantiqueira. Os padrões eletroforéticos observados nos zimogramas coincidem com os descritos por Lefèvre \& Charrier (1993a) e Silva (2000). O último autor avaliou 55 das 141 etnovariedades analisadas no presente trabalho, através da técnica de isoenzimas em gel de poliacrilamida em gradiente, sistema esse mais preciso para interpretação dos padrões eletroforéticos.

De acordo com Brown (1978) o emprego dos marcadores bioquímicos como as isoenzimas têm sido utilizados em estudos de diversidade genética em populações naturais a partir de amostragens genéticas, pois esses marcadores apresentam características de neutralidade, codominância e não interferência do ambiente nas avaliações. Por apresentar essas características, os marcadores foram utilizados para estimar a diversidade genética nas populações não naturais constituídas pelas roças de etnovariedades de mandioca.
Os marcadores isoenzimáticos, por sua quase neutralidade, permitem caracterizar forças evolutivas que constituem eventos determinantes na organização da variabilidade genética de populações, sem a influência da seleção, possibilitando maior compreensão das mesmas. Apesar das restrições quanto à utilização destes marcadores para a obtenção de estimativas de diversidade, os mesmos têm se mostrado bastante eficientes na caracterização da dinâmica evolutiva de roças de agricultura tradicional autóctone (Faraldo, 1994; Sambatti, 1998; Peroni, 1998), bem como na caracterização da dinâmica da movimentação de alelos em populações (Santos, 1994; Silva, 2000).

As freqüências gênicas estão relacionadas com fatores geográficos, ambientais, históricos e sistema de cruzamento. Porém, as freqüências não permitem responder como a variabilidade é mantida dentro da população, contudo fornecem informações relacionadas com as forças de atuação da seleção.

Os valores encontrados na TABELA 2 para as estimativas dos índices de diversidade, número médio de alelos por loco, heterogeneidade observada e esperada e índice de fixação, podem ser considerados relativamente elevados quando comparados com outras culturas, espécies arbóreas de populações naturais (Hamrick \& Godt, 1989) e a própria mandioca (Lefèvre \& Charrier, 1993a,b).

Segundo Nei (1978), o número médio de alelos por loco (A) é muito influenciado pelo tamanho da amostragem genética (número de loco) na coleta. A análise da variabilidade genética detectou média de 2,1 alelos por loco. O valor obtido pode ser considerado alto quando comparado ao valor aproximado de 1,78 encontrado por Lefèvre \& Charrier (1993a) no gênero Manihot. Os autores trabalharam com amostragem semelhante ao utilizado no presente estudo.

Comparando-se a magnitude desses índices ao encontrado para as espécies vegetais, que é de $50 \%$ (Hamrick \& Godt, 1989), quando analisaram 473 espécies diferentes, pode-se considerar que as regiões de coleta de etnovariedades de mandioca apresentam alto polimorfismo.

A heterozigosidade média observada nas regiões geográficas variou de 0,320 (Rio Negro) a 0,414 (São Paulo) com valor médio de 0,354. Os valores de Ho mostraram-se pouco contrastantes entre si, entre as regiões amostradas (TABELA 2).

A heterozigosidade observada é um índice de diversidade genética muito influenciado pelo sistema reprodutivo da espécie. Uma população natural de espécie alógama apresenta maior heterozigose do que uma população de espécie autógama. $O$ fato de ser encontrado maior heterozigosidade no grupo de etnovariedades originado do Estado de São Paulo pode ser decorrente do surgimento de recombinantes da reprodução sexuada e posterior incorporação desse material nas roças ou pelo efeito fundador, ou seja, as roças teriam sido implantadas a partir de material heterozigoto e mantido via propagação 
TABELA 2 - Variabilidade genética observada a partir de 15 locos isoenzimáticos polimórficos detectada em 141 etnovariedades de mandioca ( $M$. esculenta) provenientes de sete regiões geográficas do Brasil.

\begin{tabular}{lccccc}
\hline \multicolumn{1}{c}{ População } & $\begin{array}{c}\text { Tamanho da } \\
\text { amostra }\end{array}$ & $\begin{array}{c}\text { Número médio de } \\
\text { alelos por loco }\end{array}$ & $\begin{array}{c}\text { Heterozigosidade } \\
\text { média observada }\end{array}$ & $\begin{array}{c}\text { Hete rozigosidade } \\
\text { média esperada }\end{array}$ & $\begin{array}{c}\text { Índice de } \\
\text { Fixação } f\end{array}$ \\
\hline 1. Rio Negro & 25 & 2,1 & $0,320 \pm 0,054$ & $0,443 \pm 0,031$ & 0,278 \\
2. Rio Branco & 9 & 2,1 & $0,348 \pm 0,075$ & $0,443 \pm 0,036$ & 0,214 \\
3. Mato Grosso & 22 & 2,1 & $0,361 \pm 0,076$ & $0,405 \pm 0,036$ & 0,109 \\
4. Rio Solimões & 15 & 2,1 & $0,356 \pm 0,061$ & $0,431 \pm 0,028$ & 0,174 \\
5. São Paulo & 14 & 2,1 & $0,414 \pm 0,076$ & $0,446 \pm 0,031$ & 0,072 \\
6. Pará & 40 & 2,2 & $0,355 \pm 0,059$ & $0,409 \pm 0,035$ & 0,132 \\
7. Xingu & 17 & 2,1 & $0,322 \pm 0,062$ & $0,328 \pm 0,041$ & 0,018 \\
\hline Média & - & 2,1 & $0,354 \pm 0,066$ & $0,415 \pm 0,034$ & 0,142 \\
\hline
\end{tabular}

vegetativa ao longo do tempo. Elevado valor de heterozigosidade (Ho) foi também obtido em etnovariedades de mandioca originadas do Estado de São Paulo, através de marcadores de DNA do tipo microsatélite (Mühlen, 1999).

Autores como Weir (1996) e Nei (1973) consideram a freqüência de heterozigotos um importante indicador de diversidade genética, pois cada heterozigoto carrega alelos diferentes representando melhor a variação existente tanto em populações de espécies autógamas como alógamas. Os autores basearam a hipótese em populações naturais, contudo no presente trabalho, estamos trabalhando com populações formadas por propagação vegetativa, o que pode invalidar a hipótese, em decorrência do efeito fundador.

A heterozigosidade esperada ( $\mathrm{He}$ ou h) ou diversidade alélica é um índice de diversidade que não sofre influência do sistema reprodutivo e pode ser utilizado para comparação da diversidade genética entre espécies de diferentes formas de reprodução. A diversidade alélica variou de 0,328 (Xingu) a 0,446 (São Paulo), com média de 0,415 . A variação na diversidade genética entre as regiões não foi significativa, utilizando o critério que considera a adição e subtração de duas vezes o desvio padrão das médias, havendo sobreposição das amplitudes de variação das diferentes regiões geográficas.

A diferença de diversidade alélica entre as populações não foi diferente, possivelmente, em decorrência dos altos valores obtidos para os desvios padrão, ainda assim, se considerarmos apenas uma vez o desvio padrão, constata-se que o grupo de etnovariedades originadas do Parque Indígena do Xingu apresenta menor variabilidade genética. As etnovariedades coletadas nas roças cultivadas na Região Amazônica possuem todos os alelos presentes nas demais regiões, sendo que o inverso não é verdadeiro.

A heterozigosidade esperada encontrada pode ser considerada alta, pois numa população com média de 2,1 alelos por loco é possível obter heterozigosidade máxima de 0,526 e foi encontrado 0,415 . Portanto, $78,75 \%$ da heterozigose possível. A espécie apresenta alto nível de polimorfismo: a heterozigosidade estimada está de acordo com os valores encontrados para as espécies de polinização cruzada (Brown, 1989).
Na TABELA 2, observam-se também os valores do índice de fixação, onde constata-se que as populações estudadas apresentam, em média, excesso de homozigose $(0,142)$, em relação ao esperado para uma população em equilíbrio de Hardy-Weinberg com essas características. O equilíbrio de Hardy-Weinberg foi usado somente como referencial, pois como o material é de propagação vegetativa a estrutura observada dificilmente poderá ser repetida, ou seja, não é possível esperar encontrar essas proporções em gerações futuras.

Os valores de $G_{S T}$ para a distribuição da variação genética entre as regiões revelou que $8,80 \%$ da variabilidade genética total está contida entre populações (regiões), consequentemente, $91,20 \%$ da variabilidade está concentrada dentro das regiões (TABELA 3), resultado que coincide com a distribuição da variabilidade genética em populações naturais de espécies alógamas (Futuyma, 1992).

Cury (1993) e Martins (1994) propuseram o modelo da "Dinâmica evolutiva da mandioca", o qual leva em consideração o fato da cultura apresentar sistema reprodutivo sexual capaz de gerar recombinantes dentro das roças. Dessa forma, genótipos diferentes são gerados, mantidos e incorporados ao conjunto gênico da espécie. Portanto, a roça é considerada a unidade evolutiva onde atuam os processos de geração e amplificação da variabilidade, sendo esperado que a variabilidade genética esteja concentrada dentro da roça.

A distribuição da diversidade genética entre e dentro das populações depende do fluxo gênico e dos mecanismos de reprodução nas plantas. A maior concentração da variabilidade genética dentro das regiões, está possivelmente relacionado com a ocorrência de fluxo gênico entre as populações, como consequência da troca ou introdução de material (etnovariedades) nas roças.

A variabilidade encontrada nas roças de mandioca pode ser a explicação do grande poder de adaptação da espécie em diferentes ambientes. Marcon (1988) relata que a variabilidade genética dentro das populações tem maior flexibilidade de resposta à situações temporárias de estresses. 
TABELA 3 - Variabilidade genética observada nas 7 regiões de coleta das etnovariedades de mandioca $(M$. esculetna) para 15 locos isoenzimáticos analisados.

\begin{tabular}{lccc}
\hline Loco enzimático & $\mathrm{D}_{\mathrm{ST}}$ & $\mathrm{H}_{\mathrm{T}}$ & $\mathrm{G}_{\mathrm{ST}}$ \\
\hline Aat-1 & 0,022 & 0,497 & 0,045 \\
Cap-1 & 0,049 & 0,430 & 0,113 \\
Mdh-1 & 0,014 & 0,216 & 0,063 \\
Madh-1 & 0,019 & 0,360 & 0,053 \\
Skdh-1 & 0,083 & 0,674 & 0,123 \\
Pgi-1 & 0,045 & 0,460 & 0,097 \\
Pgi-2 & 0,033 & 0,482 & 0,068 \\
Me-1 & 0,014 & 0,485 & 0,028 \\
Me-2 & 0,017 & 0,468 & 0,036 \\
Acp-1 & 0,067 & 0,438 & 0,153 \\
Acp-2 & 0,105 & 0,462 & 0,228 \\
G6pdh-1 & 0,047 & 0,488 & 0,095 \\
G6pdh-2 & 0,028 & 0,405 & 0,069 \\
Idh-1 & 0,032 & 0,262 & 0,121 \\
Pgm-1 & 0,013 & 0,495 & 0,026 \\
\hline Média & 0,039 & 0,441 & 0,088 \\
\hline Desvio & 0,002 & 0,007 & 0,004 \\
\hline D
\end{tabular}

$D_{S T}=$ diversidade genética média entre as regiões; $H_{T}=$ diversidade genética total; $\mathrm{G}_{\mathrm{ST}}=$ proporção de diversidade entre populações.

Hamrick (1985), referindo-se a populações naturais, afirma que o fluxo gênico homogeneiza a variabilidade genética entre elas e reduz os efeitos aleatórios da deriva genética. Os resultados encontrados, no presente trabalho, apresentam base de sustentação para aceitar que esse conceito também pode ser aplicado para populações não naturais de mandioca, pois as técnicas agrícolas utilizadas no manejo da agricultura tradicional não eliminam as pressões da seleção natural (Cury, 1993).

A análise de agrupamento resultou a formação de 3 grupos distintos (1, 2 e 3). O primeiro grupo formado pelas roças originadas da Região Amazônica (Rio Negro, Rio Branco, Rio Solimões, Estado de Mato Grosso e Estado do Pará); o segundo constituído apenas pelas etnovariedades coletadas nas roças do litoral Sul do Estado de São Paulo; e o terceiro composto pelas etnovariedades coletadas nas roças da Região do Parque Indígena do Xingu (Figura 1).

O grupo 1 revelou grande similaridade entre as plantas deste grupamento possivelmente por representar uma área de intensa migração de índios e caboclos, o que estaria promovendo intercâmbio de material genético e, consequentemente, tornando as populações mais similares. No grupo 2, observa-se uma estreita relação entre as etnovariedades do Estado de São Paulo com as etnovariedades da Região Amazônica que constituem o grupo 1, demonstrando afinidade genética e sugerindo que

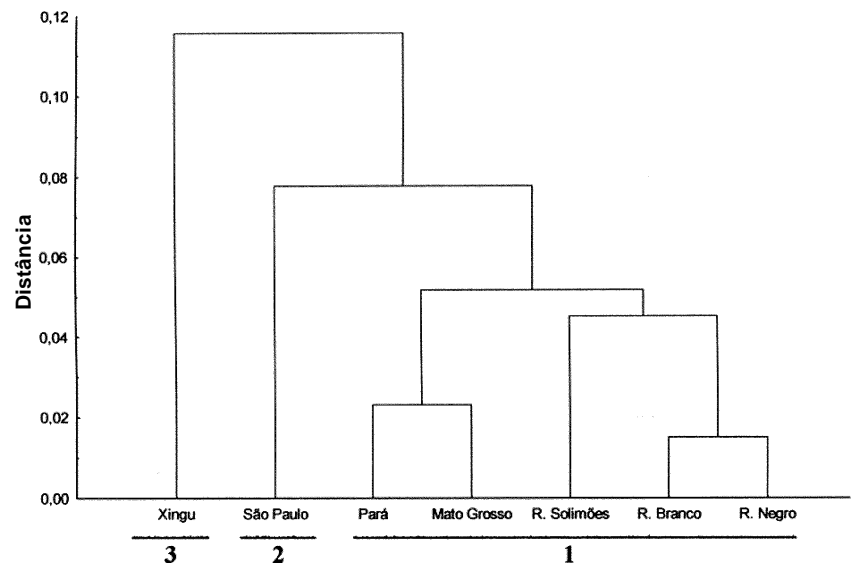

Figura 1 - Dendrograma resultante da análise de agrupamento por padrões de distância das regiões geográficas, utilizando-se coeficientes de Distância Euclidiana Simples e algoritimo U.P.G.M.A, em etnovariedades de mandioca (Manihot esculenta).

o material cultivado no Estado de São Paulo pode ter sido originado da Região Amazônica. O grupo 3 é constituído por roças que foram por muito tempo mantidas em área restrita e isolada, formadas principalmente por material trocado entre membros de tribos vizinhas.

Portanto, a distribuição da variabilidade genética de mandioca nas áreas amostradas está relacionada às regiões geográficas conforme observado em outras espécies, como por exemplo em espécies do gênero Stylosanthes (Marcon, 1988).

É verdade que não existe grande diversidade entre roças das diferentes regiões geográficas, pois o nível de distância genética foi pequena (13\%), contudo essa diferença pode se tornar maior se não houver fluxo gênico entre elas, realizado pelo intercâmbio de material, pois existe uma tendência de que seja plantado em maior área as variedades melhoradas comercialmente.

Os resultados encontrados, no presente trabalho, constatam a existência de grande variabilidade genética nas roças de etnovariedades, contudo somente $2 \%$ das etnovariedades de mandioca são utilizadas em programas de melhoramento da espécie (Hershey, 1992). O percentual encontrado poderá ser considerado alto, pois a utilização de material originado de roças locais em programas de melhoramento de outras espécies está em torno de $1 \%$ (Hershey, 1992).

A análise de locos isoenzimáticos em estudos de populações tem permitido aumentar o nível de conhecimento da estrutura genética de populações de plantas. Os padrões de distribuição de variação genética dentro e entre populações estão mais claros e evidentes nos dias de hoje. A utilização de variação aloenzimática em conjunto com outros marcadores moleculares, permite obter dados que explicam a influência do sistema de cruzamento em plantas, dispersão de sementes e sobrevivência diferencial na estrutura genética de populações de plantas (Hamrick \& Godt, 1989). 
É possível inferir que o agricultor mantém e amplifica a variabilidade genética nas roças de agricultura tradicional autóctone. A diversidade é mantida em função do interesse do agricultor em preservar e conservar determinados genótipos. É interessante ressaltar que a maioria dos agricultores está preocupada em manter etnovariedades como um pequeno banco de germoplasma in situ, como constatado por Sambatti (1998) em roças alteradas e não alteradas na região de Ubatuba do litoral Norte do Estado de São Paulo.

Brush (1992) e Salick (1992, 1995, 1997) enfatizaram a importância de conservar a diversidade local e manter as práticas agrícolas tradicionais paralelas com as práticas agrícolas modernas, que muito contribuem para o aumento e manutenção da variabilidade, evitando dessa forma a erosão genética.

Os resultados do presente trabalho confirmam a grande variabilidade fenotípica observada em mandioca através de caracteres morfológicos (Cury, 1993) sendo que essa variabilidade deve estar relacionada com o modo de reprodução, a dispersão e armazenamento das sementes no solo (banco de sementes), que permitem a introdução de novos recombinantes no conjunto original de variabilidade da espécie. Segundo Cury (1993), o surgimento de variabilidade seria também função da interação entre mutação, migração, hibridação interespecífica, e principalmente hibridação intraespecífica, com os processos de manejo agrícola. Além disso, Rogers $(1965 ; 1972)$ afirma que, nas áreas onde o material cultivado de $M$. esculenta é mantido, são encontradas numerosas espécies silvestres que podem cruzar com a mandioca e originar raças colonizadoras.

Os resultados mostram divergência genética entre as regiões amostradas, relacionada possivelmente com o manejo das roças, migração de material genético e introdução de cultivares realizada pelo homem (troca de etnovariedades). Segundo Cury (1993), a migração de material é uma das responsáveis pelo fluxo gênico entre diferentes roças de mandioca e regiões geográficas, pois a dispersão natural de sementes e gametas via pólen é muito limitada.

Portanto, existe tendência de que as etnovariedades da Região Amazônica apresentam maior variabilidade genética que as roças originadas da Região do Parque Indígena do Xingu e que a maior parte da variabilidade genética das etnovariedades de mandioca está concentrada dentro das regiões geográficas, e a hipótese de grande diversidade genética dentro das regiões geográficas postulada pelo modelo de dinâmica evolutiva da mandioca, apresentado por Cury (1993) e Martins (1994) foi confirmada.

\section{REFERÊNCIAS BIBLIOGRÁFICAS}

ALFENAS, A.C.; PETERS, I.; BRUNE, W.; PASSADOR, G.C. Eletroforese de proteínas e isoenzimas de fungos e essências florestais. Viçosa: UFV, 1991. 242p.
BORSOI FILHO, J.L. Variabilidade isoenzimática e divergência genética de seis cultivares de mandioca (Manihot esculenta Crantz). Viçosa, 1995. 52p. Tese (Doutorado) - Universidade Federal de Viçosa.

BROWN, A.H.D. Isozymes, plant population genetic structure, and genetic conservation. Theoretical and Applied Genetics, v.52, p.145-157, 1978.

BROWN, A.H.D. Genetic characterization of plant mating systems. In: tructure, and genetic conservation. In: CLEGG, M.T.; KAHLER, A.L.; WEIR, B.S. (Ed.) Plant population genetics, breeding and genetic resources. Sunderland: Mass, 1989. p.145-162.

BRUSH, S.B. Ethnoecology, biodiversity, and modernization in Andean potato agriculture. Journal of Ethnobiology, v.12, p.161-185, 1992.

CLAYTON, J.; TRETIAK, D. Amine-citrate buffers for $\mathrm{pH}$ control in starch gel electrophoresis. Journal of the Fisheries Research Board of Cannada, v.29, p.1169-1172, 1972.

CLEVELAND, D.A.; SOLERI, D.; SMITH, E.S. Do folk crop varieties have a role in sustainable agriculture? BioScience, v.44, p.740-751, 1994.

CURY, R. Dinâmica evolutiva e caracterização de germoplasma de mandioca (Manihot esculenta Crantz), na agricultura autóctone do Sul do Estado de São Paulo. Piracicaba, 1993. 103p. Dissertação (Mestrado) - Escola Superior de Agricultura "Luis de Queiroz", Universidade de São Paulo.

FARALDO, M.I.F. Caracterização isoenzimática e diversidade de etnovariedades de mandioca (Manihot esculentas Crantz). Piracicaba, 1994. 91p. Dissertação (Mestrado) - Escola Superior de Agricultura "Luiz de Queiroz", Universidade de São Paulo.

FERRAZ, E.M.; GANDARA, F.B.; CUNHA, N.L.; REIS, M.S.; KAGEYAMA, P.Y. Eletroforese de isoenzimas para espécies arbóreas: manual de laboratório. Piracicaba: ESALQ, Depto. de Ciências Florestais, Lab. de Biologia Reprodutiva e Genética de Espécies Arbóreas, 1994. 23p.

FUTUYMA, D.J. Biologia evolutiva. 2.ed. Ribeirão Preto: SBG, 1992. 631p.

HAMRICK, J.L. Isozymes and analysis of genetic structure in plants populations. In: SOLTIS, D.E.; SOLTIS, P.S. (Ed.) Isozyme in plant biology. Portland: Dioscorides Press, 1985. p.87-105.

HAMRICK, J.L.; GODT, M.J.W. Allozyme diversity in plant species. In: SOLTIS, D.E.; SOLTIS, P.S. (Ed.) Isozymes in plant biology. Portland: Discorides Press, 1989. p.43-63.

HERSHEY, C.H. Manihot esculenta diversity. In: INTERNATIONAL NETWORK FOR CASSAVA GENETIC RESOUCES, Cali, Proceedings. Rome: IBPGR, 1992. p.111-134.

HERSHEY, C.; AMAYA, A. Germoplasma de yuca: Evolución, distribución y colección. In: DOMINGUEZ, C.E. Yuca: investigación, produción y utilzación. Cali: CIAT, 1989. p.77-79.

HUSSAIN, A.; BUSHUK, W.; RAMIREZ, H.; ROCA, W. Identification of cassava (Manihot esculenta Crantz) cultivars by electrophoretic patterns of esterase isozymes. Seed Science and Technology, v.15, p.19-22, 1987.

LEFÈVRE, F.; CHARRIER, A. Heredity of seventeen isozyme loci in cassava (Manihot esculenta Crantz). Euphytica, v.66, p.171-178, 1993a.

LEFÈVRE, F.; CHARRIER, A. Isozymes diversity within Africa Manihot germplasm. Euphytica, v.66, p.73-80, 1993b.

MARCON, G. Estrutura genética de populações de Stylosanthes humilis H.B.K. (Leguminosae) de três regiões ecogeográficas do Estado de Pernambuco. Piracicaba, 1988. 179p. Tese (Doutorado) - Escola Superior de Agricultura "Luiz de Queiroz", Universidade de São Paulo. 
MARTINS, P.S. Biodiversity and agriculture: patterns of domestication of brazilian native plants species. Anais da Academia Brasileira de Ciências, v.66, p.219-226, 1994. Suplemento 1.

MÜHLEN, G.S. Avaliação da diversidade genética de etnovariedades de mandioca (Manihot esculenta Crantz) com marcadores de DNA: RAPD, AFLP e MICROSSATÉLITES. Piracicaba, 1999. 176p. Tese (Doutorado) - Escola Superior de Agricultura "Luiz de Queiroz", Universidade de São Paulo.

$\mathrm{NEI}, \mathrm{M}$. Analysis of gene diversity in subdivided populations. Proceedings of the National Academy of Sciences of the United States of America, v.70, p.3321-3323, 1973.

NEI, M. Estimation of averege heterozygosity and genetic distance from a small number of individuals. Genetics, v.89, p.583-590, 1978.

PERONI, N. Taxonomia folk e diversidade intra-específica de mandioca (Manihot esculenta Crantz) em roças de agricultura tradicional em áreas de Mata Atlântica do sul do Estado de São Paulo. Piracicaba, 1998. 191p. Dissertação (Mestrado) - Escola Superior de Agricultura "Luiz de Queiroz", Universidade de São Paulo.

RAMIREZ, H.; HUSSAIN, A.; ROCA, W.; BUSHUK, W. Isozyme electrophoregrams of sixteen enzymes in five tissues of Cassava (Manihot esculenta Crantz) varieties. Euphytica, v.36, p.39-48, 1987.

ROGERS, D.J. Some botanical and ethnological considerations of Manihot esculenta. Economic Botany, v.19, p.369-377, 1965.

ROGERS, D.J. Some further considerations on the origin of Manihot esculenta Crantz. Tropical Root and Tuber Crops Newsletter, v.6, p.4-14, 1972.

SALICK, J. Crop domestication and evolutionary ecology of cocona (Solanum sessiliflorum Dunal). In: HEICHT, M.K. (Ed.) Evolutionary biology. New York: Plenum Press, 1992. p.247-285.

SALICK, J. Toward an integration of evolutionary ecology and economic botany: personal perspectives on plant/people interations. Annals of the Missouri Botanical Garden, v.82, p.25-33, 1995.
SALICK, J.; CELLINESE, N.; KNAPP, S. Indigenous diversity of cassava: generation, maintainance, use and loss among Amuesha, peruvian upper Amazon. Economic Botany, v.51, p.6-19, 1997.

SAMBATTI, J.B.M. Erosão genética e conservação de germoplasma de mandioca na agricultura autóctone em Ubatuba-SP. Piracicaba, 1998. 165p. Dissertação (Mestrado) - Escola Superior de Agricultura "Luiz de Queiroz", Universidade de São Paulo.

SANTOS, E.G. Ecologia da polinização, fluxo de pólen e taxa de cruzamento em Bauhinia forficata Link. (Caesaloiniaceae). Piracicaba, 1994. 114p. Dissertação (Mestrado) - Escola Superior de Agricultura "Luiz de Queiroz", Universidade de São Paulo.

SCANDALIOS, J.G. Genetic control of multiple molecular forms of enzymes in plants. Biochemical Genetics, v.3, p.37-79, 1969.

SILVA, R.M. Sistema reprodutivo, fluxo gênico e paternidade em roça de etnovariedades de mandioca (Manihot esculenta Crantz). Piracicaba, 2000. 131p. Tese (Doutorado) - Escola Superior de Agricultura "Luiz de Queiroz", Universidade de São Paulo.

SOLTIS, D.E.; HAUFLER, C.H.; DARROW, D.C.; GASTONY, G.J. Starch gel electrophoresis of ferns: a compilation of grinding buffers, gel and electrode buffers, and staining schedules. American Fern Journal, v.73, p.9-26, 1983.

SWOFFORD, D.L.; SELANDER, R.B. Biosys-1: a computer program for the analysis of allelic variation in population genetics and biochemical systematics. Release 1,7. Illinois Natural History, 1989.

WEIR, B.S. Genetic data analysis II: methods for discrete population genetic data. 2.ed. Sunderland: Sinaver Associates, 1996. 445p.

WENDEL, J.F.; WEEDEN, N.F. Visualization and interpretation of plant isozymes. In: SOLTIS, D.E.; SOLTIS, P.S. (Ed.) Isozymes in plant biology. London: Chapman and Hall, 1990. cap.1, p.5-45.

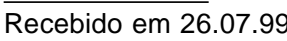

